\title{
Experimental Investigation on Sulfur Extraction from Coal Coking Waste
}

\author{
Wenfeng Hao \\ Department of Applied Chemistry, School of New Energy, Shenyang Institute of Engineering, Shenyang, China
}

Email address:

hao_wenfeng@sina.com

To cite this article:

Wenfeng Hao. Experimental Investigation on Sulfur Extraction from Coal Coking Waste. American Journal of Applied Chemistry. Vol. 5, No. 1, 2017, pp. 19-23. doi: 10.11648/j.ajac.20170501.13

Received: February 8, 2017; Accepted: February 20, 2017; Published: March 4, 2017

\begin{abstract}
During coal coking process a great deal of sulfurs are produced and are discarded to surroundings, which makes a lot of lands to be occupied and puts the environment to be polluted. In order to find multi-win production mode of coal coking for resources, surroundings and societies, carbon disulfide as an extracting agent was applied to extract sulfur from sulfur cake in this study. Final laboratory technological condition was that more than $98 \%$ sulfur yield could be gotten when the granularity of raw sulfur powder, liquid-solid ratio, extraction temperature, stirring velocity and stirring time respectively were $200 \mathrm{mesh}, 3: 1 \mathrm{~g} / \mathrm{g}$, $40^{\circ} \mathrm{C}, 200 \mathrm{rpm}$ and $30 \mathrm{~min}$.
\end{abstract}

Keywords: Coal Coking, Waste, Sulfur Extraction, Carbon Disulfide, Experiment

\section{Introduction}

Coal as an important natural resource still plays its irreplaceable role in $21^{\text {st }}$ Century, especially in those countries such as China, in which coal resources is relatively abundant [1-2]. Among those different kinds of coals, coking coal as an indispensable coal resource in metallurgical industry or in chemical industry, still has a large number market demand every year whether market economy model or planned economy model [3-5]. However, the associated elemental sulfur is also generated simultaneously while high quality coke is produced [6-8]. Currently these sulfurs mostly exist in the form of a mixture of sulfur formation and are discarded to environments. This disposal method occupies a lot of lands and pollutes the surroundings, but also it brings a huge waste of derived resources. As we know sulfur is an important raw material for the chemical, food, medicine and other industries [9-11], also there are a great deal of market demand in each year [12-13]. If these sulfurs can be recycled, then it will not only have a positive effect on our environments, but also the production chain of coal coking industry will be extended and the comprehensive utilization value of coal resources will be promoted, which will bring important economic significance to our societies. For solid mixture separation with sulfur, melting methods such as Frasch [14] and Sicilian [15-16] and sublimation methods [17] can be used to mine sulfurs from raw ore deposits with elemental sulfurs or artificial mixture materials with zero valent sulfurs. However, a large number of energies have to be consumed once these methods abovementioned are put to an industrial practice. Thus, extraction, the rest of sulfur recovery way [18], will become a method used to decrease energy consumption under environmental protection with closed cycle of solvent and to get optimized harvest for eligible sulfur product in this work because relevant investigation for those sulfurs extraction from coal coking waste isn't reported so far.

\section{Experimental}

\subsection{Apparatus and Material}

\subsubsection{Process and Apparatus}

Experimental processes included mainly procedures such as pulverizing and screening of raw material, experimental solid leaching and filter as shown in Figure 1, in which solvent ran in a closed cycle. Key procedures of the process flow chart were extraction unit and filtration unit, in which particle size of raw material and post-treatment of filter liquor and filter cake were considered carefully to improve leaching rate and to decrease solvent losses and environmental damage. 
Experimental devices including the extraction apparatuses and filter apparatuses all were conventional devices in a laboratory. The extraction device was a continuous stirred tank reactor with a $500 \mathrm{ml}$ volume. The filter device was a vacuum filtration system with a $1000 \mathrm{ml}$ volume. Screening device was a set of sieves with mesh number 60, 100, 150, 200 and 300. Schematic diagram of the extraction apparatuses, the most important equipment for this experiment, was drawn in Figure 2 to be used to show key results of the investigation. Moreover, the model number of the electrical analytical balance used in experiment was Sartorius BT223S.

\subsubsection{Material and Analysis}

Raw material was a residual waste cake with an elemental sulfur of coal coking from a coke-oven plant of Shanxi Province in China, in which mass fraction of soluble sulfur was $76 \%$ and mass fraction of insoluble substances was $24 \%$ using experimental determination method in this work. Mass faction of soluble sulfur was less than $\pm 0.1 \%$ compared to combustion analysis method. The solvent used in extraction operation, carbon disulfide, was analytical pure with mass fraction above $99.0 \%$.

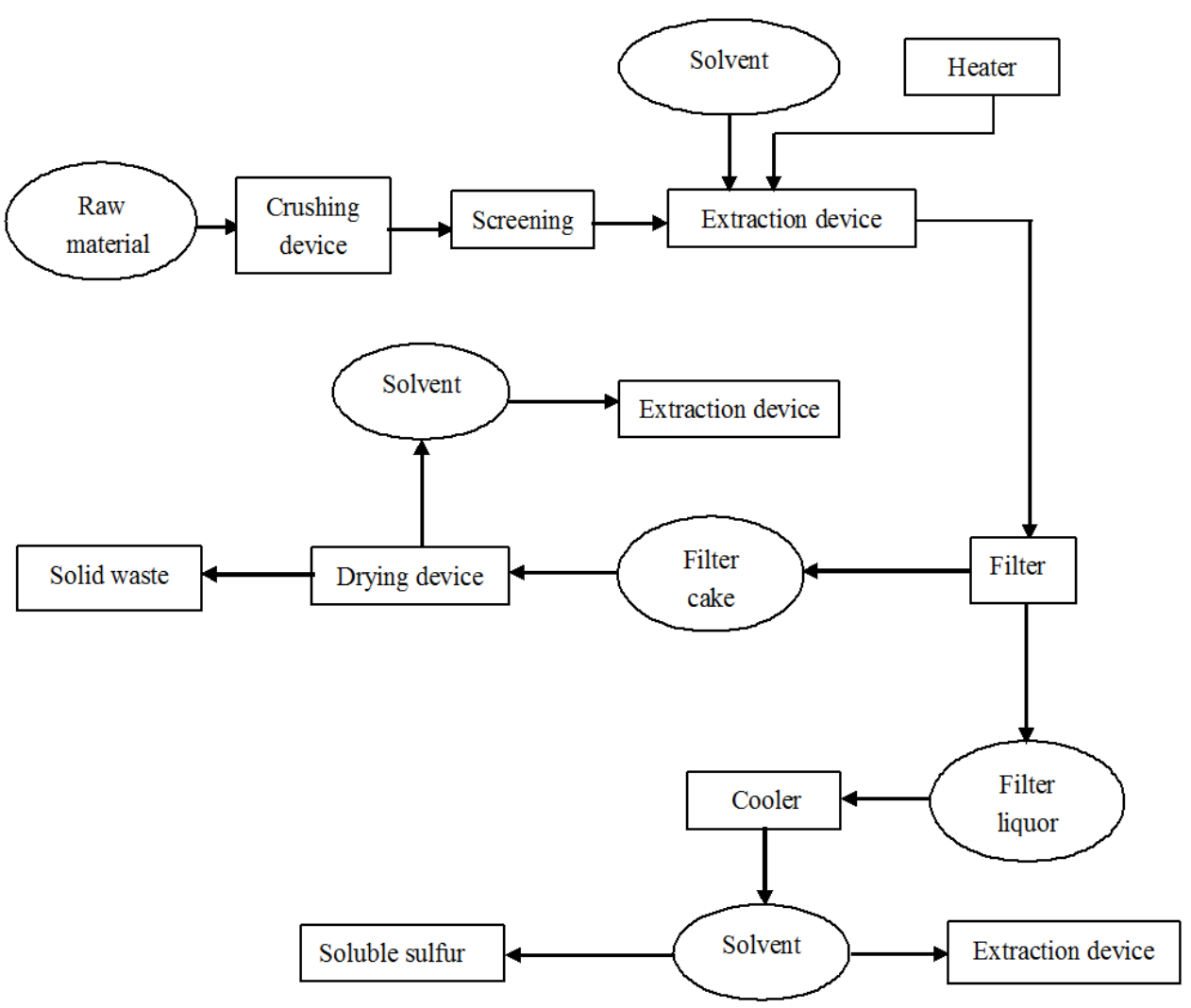

Figure 1. Schematic diagram of the process flow chart.

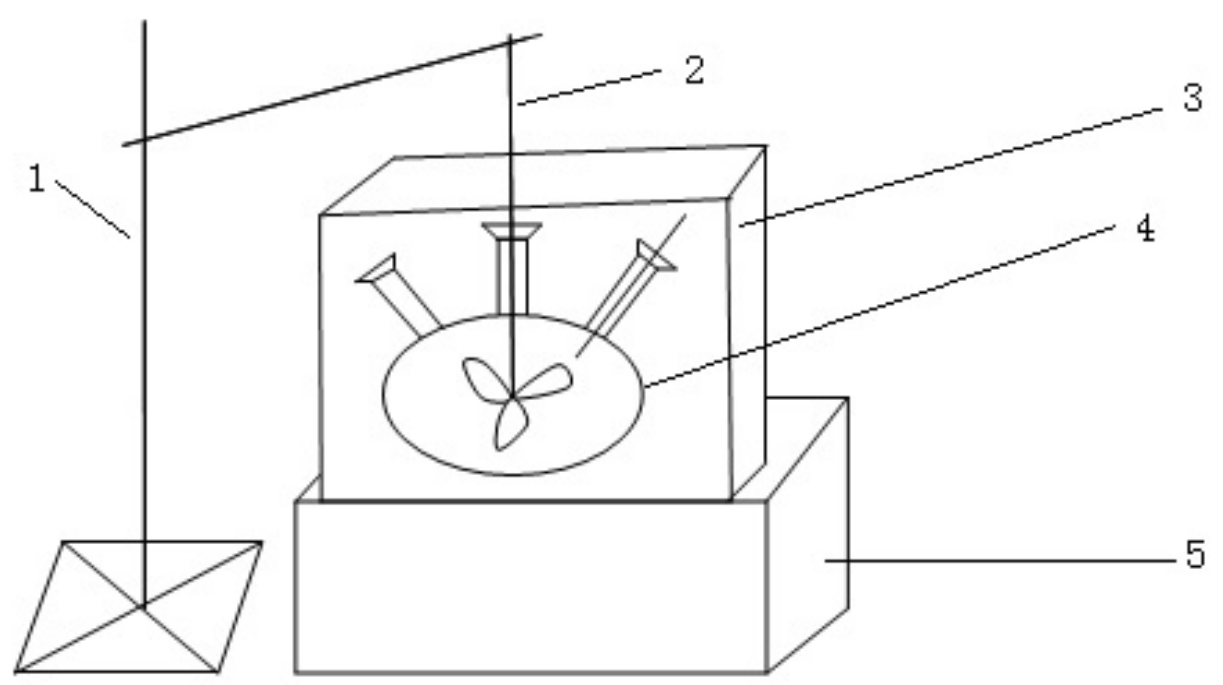

1-Iron support stand, 2-Stirrer, 3-Constant temperature water bath, 4- Three-neck flask, 5-Support platform

Figure 2. Schematic diagram of the experimental apparatus. 


\subsection{Procedure}

\subsubsection{Determination of Sulfur Content}

1) Take a certain amount sulfur cake and pulverize them in a mortar, then 60 mesh, 100 mesh, 150 mesh, 200 mesh, 300 mesh particle sizes were screened and were put aside.

2) Weigh 300 mesh sulfur cake powder $100 \mathrm{~g}$ and solvent carbon disulfide $500 \mathrm{~g}$ by electronic balance, then add them into the three-neck flask shown in Figure 2. Afterwards, adjust temperature of water bath to $50^{\circ} \mathrm{C}$ and observe thermometer's temperature in three-neck flask. When the mixture's temperature reached $45^{\circ} \mathrm{C}$ in three-neck flask, stirrer set to $150 \mathrm{rpm}$ was opened and the time was recorded to be zero time. Once the extraction time, eight hours, reached, stirrer stopped and the mixture in three-neck flask was filtered using vacuum filtration system. The filter liquor was put into a collecting bottle to be recycled. The filter cake was dried under vacuum conditions for twenty-four hours in fume cupboard and was weighed. Finally, calculate sulfur content in sulfur cake powder.

3) Repeat the above steps three times and take the average value as the sulfur content of the sulfur cake.

\subsubsection{Process}

1) Take 60 mesh $100 \mathrm{~g}$ sulfur cake as raw material and add them into three-neck flask shown in Figure 2. Also add $200 \mathrm{~g}$ the carbon disulfide liquid into the three-neck flask. Afterwards, adjust temperature of water bath to $40^{\circ} \mathrm{C}$ and open stirrer set to $150 \mathrm{rpm}$. When the mixture's temperature reached $35^{\circ} \mathrm{C}$ in the three-neck flask, the time was recorded to be zero time. After $15 \mathrm{mins}$ the stirrer stopped and unloaded the mixture to vacuum filtration system. On the one hand, the filter liquor was put into a collecting bottle to be recycled. On the other hand, the filter cake was dried for twenty-four hours by vacuum drying system vacuum in fume cupboard and the filter cake dried was weighed. Finally, sulfur yield were calculated.

2) Take sulfur cake with 100 mesh, 150 mesh, 200 mesh and 300 mesh to repeat procedure 1).

3) Mass of carbon disulfide liquid was adjusted to $500 \mathrm{~g}$, $400 \mathrm{~g}, 300 \mathrm{~g}$ and $100 \mathrm{~g}$ to repeat procedure 1 ).

4) Rotation rate of the stirrer was respectively set to $100 \mathrm{rpm}$, 200rpm, 300rpm and 0rpm to repeat procedure 1).

5) Stirring time of the stirrer was adjusted to $30 \mathrm{~min}, 45 \mathrm{~min}$, and $60 \mathrm{~min}$ to repeat procedure 1).

6) Extraction temperature was set to be $20^{\circ} \mathrm{C}, 25^{\circ} \mathrm{C}, 40^{\circ} \mathrm{C}$ and $45^{\circ} \mathrm{C}$ to repeat procedure 1 ).

7) The process parameters of the experiments were identified and three times experiments repeated were done.

\section{Results and Discussion}

\subsection{Effect of Particle Size on Sulfur Yield}

Using five-group data of particle size on sulfur yield schematic diagram of effect of particle size on sulfur yield was plotted, as shown in Figure 3. As seen from Figure 3, the sulfur yield increased with the decreasing of particle size of the raw material. When the particle size was 60 mesh, the sulfur yield was 0.589 . When the particle size was 300 mesh, the sulfur yield was increased to 0.901 . From the slope of the curve, it could be seen that the yield of sulfur had little effect after the particle size reached above 200 mesh and the cost of crushing and of screening would increase. Thus, 200 mesh was selected as the granularity size of the following experimental raw materials.

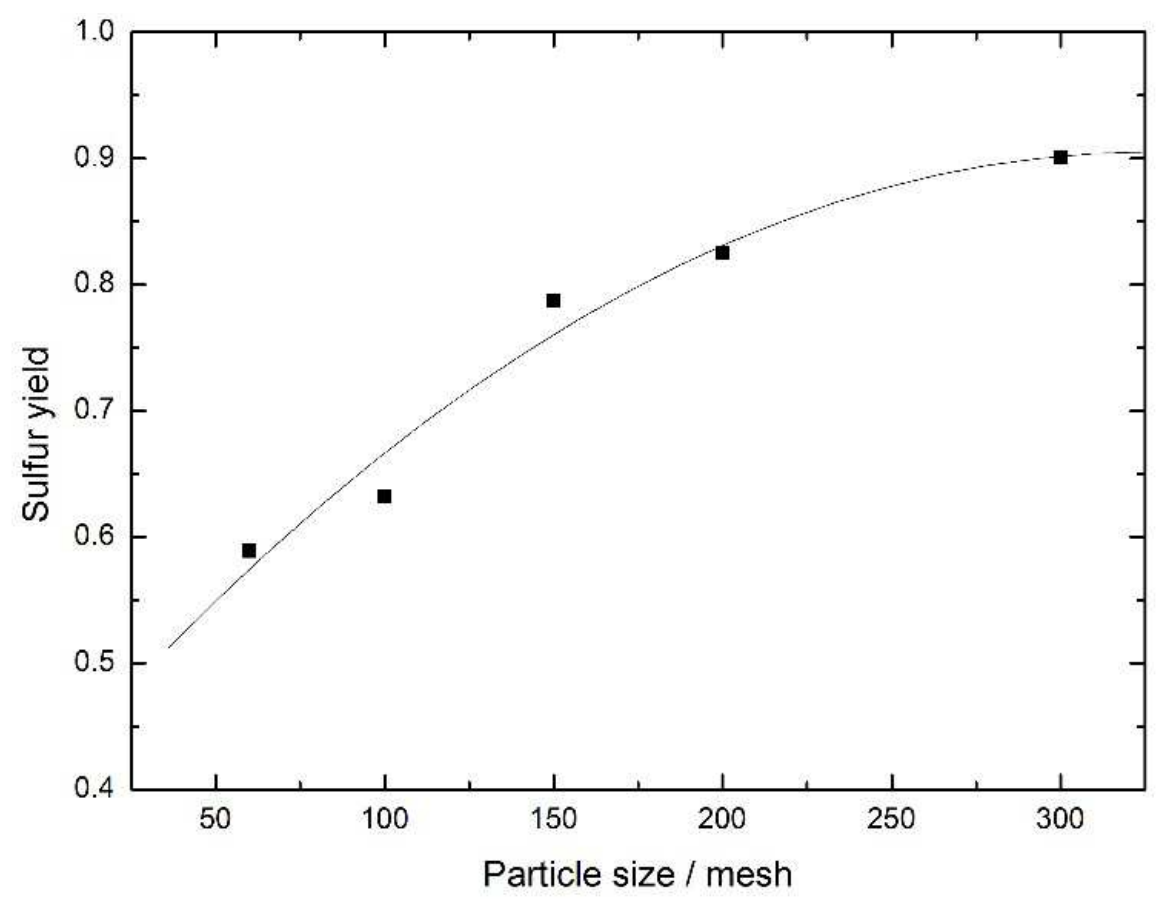

Figure 3. Effect of particle size on sulfur yield. 


\subsection{Effect of Liquid-Solid Ratio on Sulfur Yield}

Schematic diagram of effect of particle size on sulfur yield was drawn, as shown in Figure 4 by using five-group data of liquid-solid ratio on sulfur yield. As seen from Figure 4, the sulfur yield increased firstly and then decreased with the increase of liquid-solid ratio. The curve could be represented to be a parabola. When the liquid-solid ratio was $1: 1$, the sulfur yield was 0.356 . When the liquid-solid ratio was $4: 1$, the sulfur yield was 0.980 . When the liquid-solid ratio was $5: 1$, the sulfur yield was 0.991 . It could be seen from the experimental data that sulfur yield had no influence by liquid-solid ratio and thus the cycle cost would be increased if the liquid-solid ratio was too large. Therefore, $3: 1$ was selected as the liquid-solid ratio of the following experiment.

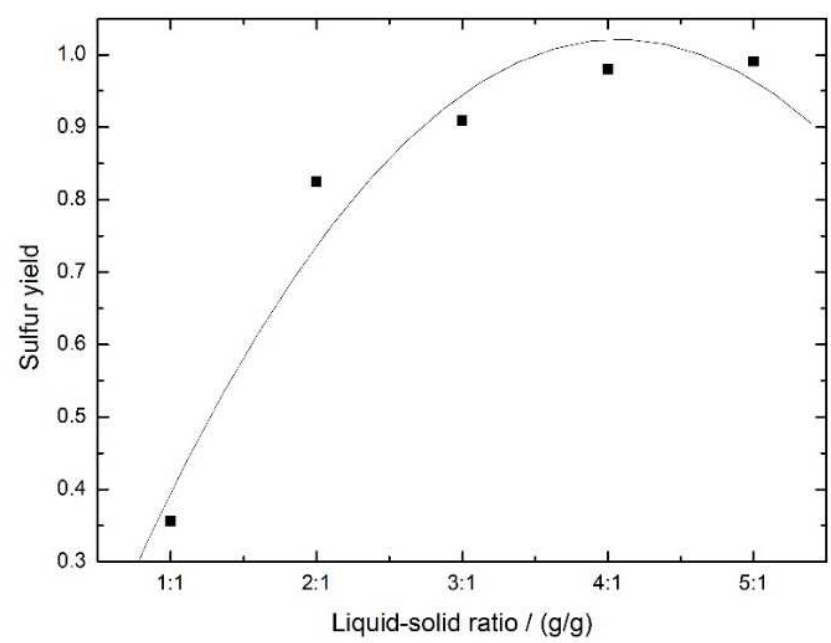

Figure 4. Effect of liquid-solid ratio on sulfur yield.

\subsection{Effect of Stirring Rate and Stirring Time on Sulfur Yield}

The effect of stirring on sulfur yield was studied in two-group experiments, which included respectively experimental data groups of stirring rate's effect and stirring time's effect on sulfur yield. Figure 5 , an effect curve of stirring rate on sulfur yield, and Figure 6, an effect curve of stirring time on sulfur yield, were drawn using those two-group data with five experimental points. As seen in Figure 5, following results could be written: the sulfur yield was 0.503 when there was no stirring. When the stirring rate was increased to $200 \mathrm{rpm}$, the sulfur yield was 0.923 . When the stirring rate was further increased to $300 \mathrm{rpm}$, the sulfur yield was 0.980 . The tendency of this sulfur yield was from low value to high value with the increase of the stirring rate. However, the slope of the curve didn't have larger change after the stirring rate 200rpm and this brought the increase of power cost. Therefore, 200rpm was used to become experimental stirring rate of following experiment.

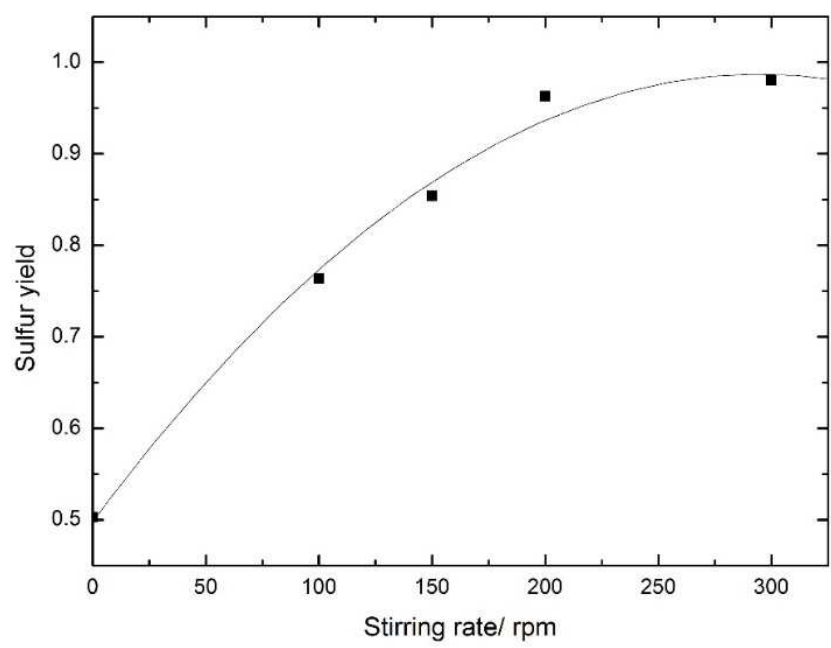

Figure 5. Effect of stirring rate on sulfur yield.

Moreover, the stirring time had a great influence on sulfur yield from Figure 6 . When the stirring time was zero, the sulfur yield was 0.503 . With the increase of the stirring time, the sulfur yield also increased, but if the stirring time was too long, there was little effect on the sulfur yield and the operation cost was increased subsequently. In experiment when the stirring time respectively was $30 \mathrm{~min}, 45 \mathrm{~min}$ and $60 \mathrm{~min}$, the sulfur yield all was about 0.99 . Thus, $30 \mathrm{~min}$ was selected as stirring time for following experiment.

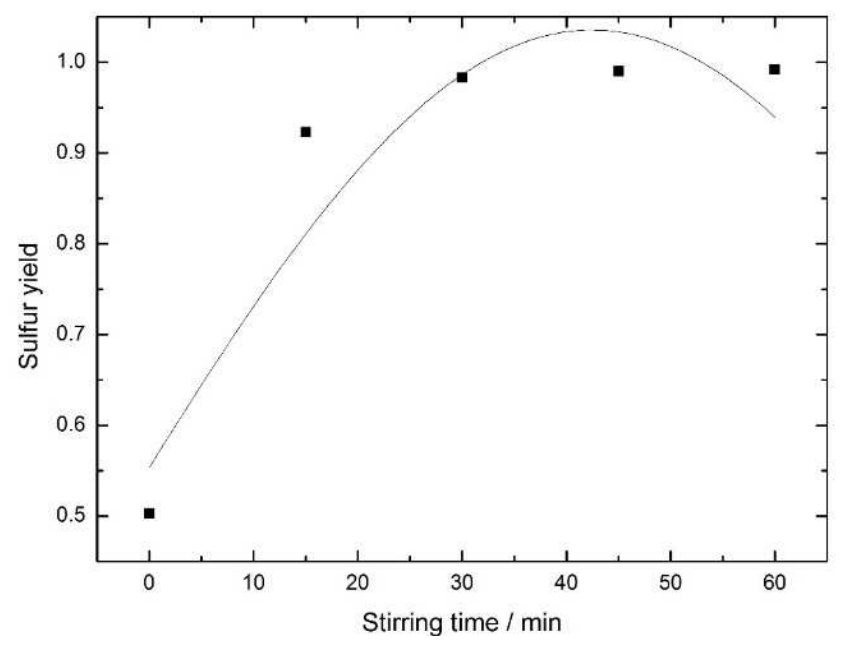

Figure 6. Effect of stirring time on sulfur yield.

\subsection{Effect of Extraction Temperature on Sulfur Yield}

Schematic diagram of effect of extraction temperature on sulfur yield was drawn in terms of one-group corresponding experimental data, as shown in Figure 7. From the curve in the graph sulfur yield changes were from 0.689 to 0.993 when extraction temperature were from $20^{\circ} \mathrm{C}$ to $45^{\circ} \mathrm{C}$. Also the curve were changed in parabolic form. Above $99 \%$ sulfur yield could be gained when extraction temperature was $40^{\circ} \mathrm{C}$. Finally, $40^{\circ} \mathrm{C}$ was selected to be a technological point of extraction temperature. 


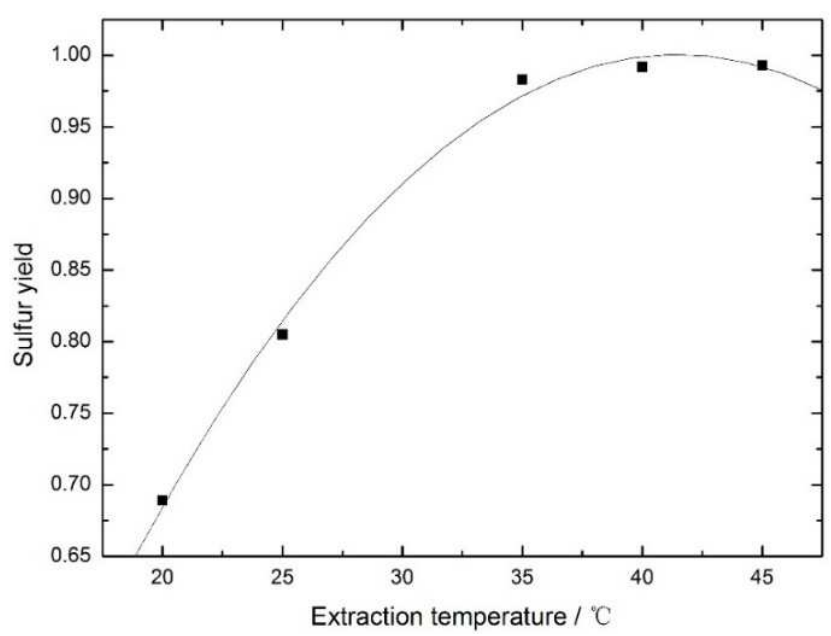

Figure 7. Effect of extraction temperature on sulfur yield.

\subsection{Verification Experiment}

After three verification experiments were done under above selected technological conditions, the results showed that more than $98 \%$ sulfur yield could have been gotten. Moreover, combustion analysis of sulfur products showed that product sulfur purity also had been more than $99.0 \%$.

\section{Conclusions}

From results and discussion of sulfur extraction experiments and process verification experiments, the following conclusions could be drawn: using carbon disulfide as an extracting agent of sulfur recovery from raw waste cake of coal coking appropriate experimental conditions was granularity size of 200 mesh of the sulfur cake, the liquidsolid ratio $3: 1(\mathrm{~g} / \mathrm{g})$, extraction temperature $40^{\circ} \mathrm{C}$, stirring rate $200 \mathrm{rpm}$ and stirring time $30 \mathrm{~min}$. Under the technological conditions more than $98 \%$ sulfur yield could have been achieved and more than $99.0 \%$ product sulfur purity also had been reached.

\section{Acknowledgements}

The financial support from United Laboratory Development Fund of China and of Liaoning Province (No. 2011), the Natural Science Foundation of Liaoning Province (No. 2013020150) and the Program for Liaoning Excellent Talents in University (No. LJQ2011134) are gratefully acknowledged.

\section{References}

[1] W. F. Hao, Study on Process Economics of Natural Resource Utilization, Natural Resources, 2016; 7, 611-627.

[2] H. H. Schobert, C. S. Song, Chemicals and materials from coal in the 21 st century, Fuel, 2002; 81, 1, 15-32.
[3] P. Bethell, B. Watters, E. Wolfe, Optimizing fine circuit design to maximize pyrite rejection and enhance coal marketability, International Journal of Coal Preparation and Utilization, 2014; 34, 3-4, 184-197.

[4] J. Trüby, Strategic behaviour in international metallurgical coal markets, Energy Economics, 2013; 36, 147-157.

[5] T. Y. Ou, C. Y. Cheng, P. J. Chen, C. Perng, Dynamic cost forecasting model based on extreme learning machine - A case study in steel plant, Computers and Industrial Engineering, 2016; 101, 544-553.

[6] H. Sun, H. B. Xia, Q. Yang, S. Du, D. D. Song, H. Z. Chang, Investigation of sulfur transformation during coking process, Advanced Materials Research, 2014; 881-883, 228-236.

[7] Z. H. Qin, H. Chen, D. J. Dai, C. S. Li, Rong L. M, Study on occurrence of organic sulfur in Xinyu clean coking coal by extraction and stripping, Journal of Fuel Chemistry and Technology, 2015; 43, 8, 897-905.

[8] Platonov, O. I. Development of the coke gas desulfurization technology, 2006 TMS Fall Extraction and Processing Division: Sohn International Symposium, 2006; 5, 193-201.

[9] J. Hong, F. Zhang, C. Xu, X. Xu, X. Li, Evaluation of life cycle inventory at macro level: a case study of mechanical coke production in China, International Journal of Life Cycle Assessment, 2015; 20, 6, 751-764.

[10] W. Huang, K. Zhang, X. Tang, Z. Zhao, H. Wan, Coking coals potential resources prediction in deep coal beds in Northern China, Energy Exploration and Exploitation, 2010, 28, 4, 313-324.

[11] C. Fan, S. Y. Long, T. Wang, Y. Y. Huang, J. Du, H. D. Yang, Y. L. Zhou, Reduction of $\mathrm{Fe}$ concentration in $\mathrm{Al}-4 \mathrm{Si}-1 \mathrm{Fe}-$ $1 \mathrm{Cu}-0.5 \mathrm{Zn}-0.5 \mathrm{Mn}$ alloys with $\mathrm{S}$, Rare Metals, 2016; 35, 4, 320-324.

[12] R. Ullrich, Alternatives for disposal and recycling of waste elemental sulfur, Air and Waste Management Association International Conference on Thermal Treatment Technologies and Hazardous Waste Combustors 2014, 2014; 184-193.

[13] P. Ruiz, T. Steele, J. Eng, Growing markets for North America, International Polyolefins Conference 2010: Finding Value in Today's Business Environment 2010, 2010; Code 81272.

[14] Edward J. Swain, U. S. refinery-sulfur production peaked in 1996, Oil and Gas Journal, 1999; 97, 10, 77-79.

[15] G. Dessau, M. L. Jensen, N. Nakai, Geology and isotopic studies of Sicilian sulfur deposits, Economic Geology, 1962; 57, $3,410-438$.

[16] V. Ferrara, The sulphur mining industry in Sicily, History of Mechanism and Machine Science, 2016; 31, 111-130.

[17] A. G. M. Ferreira, L. Q. Lobo, The low-pressure phase diagram of sulfur, Journal of Chemical Thermodynamics, 2011; 43, 2, 95-104.

[18] K. C. Hackley, D. H. Buchanan, K. Coombs, C. Chaven, C. W. Kruse, Solvent extraction of elemental sulfur from coal and a determination of its source using stable sulfur isotopes, Fuel Processing Technology, 1990; 24, C, 431-436. 